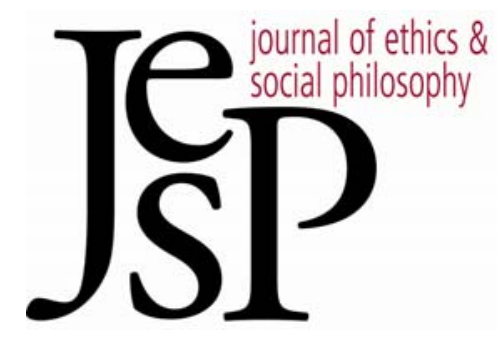

DISCUSSION NOTE

\title{
The Unusual Logic of Hurka's Recursive Account
}

BY AVRAM HILLER

Journal OF ETHICs \& Social PHILOSOPHY

DISCUSSION NOTE | MARCH 2012

URL: WWW.JESP.ORG

COPYRIGHT @ AVRAM HILLER 2012 


\title{
The Unusual Logic of Hurka's Recursive Account
}

\author{
Avram Hiller
}

HOMAS HURKA, IN HIS BOOK Virtue, Vice, and Value, and else-
where, develops a powerful recursive analysis of higher-order pleas-
ures and pains. ${ }^{1}$ The account leads Hurka to some potentially controversial conclusions. For instance, Hurka argues on its basis that some states are both good and evil and also that the view he calls the conditionality view is false. In this paper, I argue that Hurka's formulation of the recursive account is unusual and inelegant, and that Hurka reaches his conclusions only because of its peculiar aspects. I provide an alternative recursive account that is similar in spirit to Hurka's but is theoretically elegant and does not entail those conclusions.

\section{Hurka's Recursive Account}

Hurka's recursive account is based on the commonsensical idea, found in Brentano, Moore and others, that pleasure regarding something good is a good, but sadistic pleasure is an evil. Likewise, sympathetic pain regarding something evil is a good, but envious pain concerning something good is evil. Hurka provides base clauses that encapsulate basic goods and recursive clauses to account for the goodness or badness of higher-order pains and pleasures.

Here is a simplified form of Hurka's recursive account. ${ }^{2}$ First, there are two base clauses:

Base good (BG): Pleasure is good.

Base evil (BE): Pain is evil.

Next, there are four recursive clauses:

Loving good (LG): Pleasure about something good is good.

Loving evil (LE): Pleasure about something evil is evil.

Hating good (HG): Pain about something good is evil.

Hating evil (HE): Pain about something evil is good.

Using this recursive account, Hurka gives a deft argument to show that a highly intuitive principle, which he calls the "conditionality view," is false. ${ }^{3}$

1 Thomas Hurka (2001) Virtue, Vice, and Value, New York: Oxford University Press; (1998) "How Great a Good Is Virtue?" Journal of Philosophy 95(4): 181-203; and (1998) "Two Kinds of Organic Unity" Journal of Ethics 2: 299-320.

2 Hurka's recursive account is stated in Virtue, Vice, and Value, pp. 11-19; "How Great a Good Is Virtue?" pp. 198-99; and “Two Kinds of Organic Unity," p. 317. For simplicity, I focus on pains and pleasures and ignore other attitudes toward good and evil such as pursuing and desiring.

3 This form of argument is given in Virtue, Vice, and Value, pp. 147-48; "How Great a Good Is Virtue?” pp. 198-99; and “Two Kinds of Organic Unity,” pp. 318-19. 
According to the conditionality view, pleasures are not good if they are pleasures about something evil. Hurka claims that to uphold the conditionality view we need to change (BG) so that it comes after (BE) and instead reads:

$\left(\mathrm{BG}^{*}\right)$ Pleasure is good, except insofar as it is pleasure about something determined by (BE) as being evil.

This does not fully do the job, because pleasure in things that are higherorder evil is also evil. Thus advocates of the conditionality view must change $\left(\mathrm{BG}^{*}\right)$ so that it comes after $(\mathrm{LE})$ and instead reads:

(BG**) Pleasure is good, except insofar as it is pleasure about something determined by (BE) or (LE) as being evil.

Hurka then demonstrates that this will lead to a vicious circularity. In a case of an individual $C$ having sadistic pleasure in something evil, where that evil is a case of someone B experiencing envious pain in a third person A's pleasure, the view cannot show why C's pleasure is not a good. This is because the view would require (LE) to apply to a case of (HG) which in turn applies to a case of $\left(\mathrm{BG}^{* *}\right)$ - but the revised recursive account cannot have (LE) come after $\left(\mathrm{BG}^{* *}\right)$.

\section{Recursion More Generally}

The logic of Hurka's recursive definition is highly unusual. On its basis, a pleasure in something good is a good both because of (BG) and because of (LG). A pain in something good is an evil both because of (BE) and because of $(\mathrm{HG})$. Hurka asserts that his base clauses are independent of the recursive clauses, ${ }^{4}$ but there is a sense in which that is incorrect: Both the base-level clauses and the recursive clauses apply to the same states. Although this is not a fatal problem for Hurka's account, recursive definitions normally do not work that way.

For instance, recursive definitions of a WFF in propositional logic typically proceed by having, as a base clause, a rule for atomic WFFs, and then, as recursive clauses, rules for the formation of complex WFFs. Also, the recursive definition of natural numbers has " 1 is a natural number" as its base clause and "for any natural number $n, n+1$ is also a natural number." In both of these paradigmatic cases, there is no way for there to be an overlap in the scope of the base and recursive clauses. ${ }^{5}$

Consider the following first-order language whose sentential terms are capital English letters and that has one sentential connective, @. First, there is a recursive definition for forming WFFs:

4 “How Great a Good Is Virtue?” p. 198.

5 Thanks to Richard Heck for a discussion of recursion. 
(BW) Any single letter is a WFF.

(RW) For any WFFs $\boldsymbol{\Phi}$ and $\boldsymbol{\Psi}$, the string formed by adding $\boldsymbol{\Phi} @$ immediately to the left of $\boldsymbol{\Psi}$ is a WFF. ${ }^{6}$

Now, consider two axioms that indicate which WFFs have a certain characteristic, which I shall call Good $_{\mathbb{W}}$ :

(BGw) Any WFF beginning with "P" is Goodw.

(RGW) For any Goodw WFF $\boldsymbol{\Phi}$, the WFF formed by adding "P@” immediately to the left of $\boldsymbol{\Phi}$ is $\operatorname{Good}_{W}$.

On this definition, "P@P" is $\operatorname{Good}_{\mathrm{W}}$ both because 1) it accords with $\left(\mathrm{BG}_{\mathrm{W}}\right)$ and also because both 2a) "P" accords with $\left(\mathrm{BG}_{\mathrm{W}}\right)$ and $\left.2 \mathrm{~b}\right)$ "P@P" can be formed by adding "P@" to "P," in accord with $\left(\mathrm{RG}_{\mathrm{W}}\right)$. In fact, $\left(\mathrm{RG}_{\mathrm{W}}\right)$ is not even needed at all: Any WFF formed via $\left(\mathrm{RG}_{\mathrm{W}}\right)$ would be a $\operatorname{Good}_{\mathrm{W}} \mathrm{WFF}$ anyway because it accords with $\left(\mathrm{BG}_{\mathrm{W}}\right)$.

There is nothing contradictory about this recursive definition of $\operatorname{Good}_{\mathbb{W}}$ WFFs. Still, the only reason why one would want a recursive account for $\operatorname{Good}_{\mathbb{W}}$ WFFs is if not every WFF beginning with "P" is a $\operatorname{Good}_{W}$ WFF - for instance, an account on which compound WFFs beginning with "P" are Good $_{\mathrm{W}}$ only if the WFF that comes after "P@" is also $\operatorname{Good}_{\mathrm{w}}$. Thus a recursive account of Good $_{\mathbb{W}}$ WFFs, motivated in ways typical of recursive accounts, is given if $\left(B G_{W}\right)$ is simply replaced by:

(BGW1) "P" is a Goodw WFF.

On this account, the base $\operatorname{Good}_{W}$ WFFs are distinct from the complex Good $_{\mathbb{W}}$ WFFs.7 This is how recursive definitions typically work.

\section{An Alternative Recursive Account of the Good}

It should be apparent that the inelegant pair $\left(B G_{W}\right)$ and $\left(R G_{W}\right)$ are analogues to Hurka's (BG) and (LG). As I have stressed, inelegance is not a fatal problem, but it is this very inelegance that Hurka trades upon in making his circularity argument against the conditionality view. Whereas Hurka modifies (BG) for the conditionality view to claim that base goods are such that they cannot be pleasures about evil things, and then draws out a vicious circularity, there is an obvious alternative way to change $(B G)$, analogous to $\left(B G_{W} 1\right)$ :

$\left(\mathrm{BG}^{\prime}\right)$ Pleasures that are not about anything are good. ${ }^{8}$

${ }^{6}$ There should also be a closure clause: (CW) The only WFFs are those that can be established using (BW) or (RW).

7 One could also add other base clauses if atomic WFFs aside from "P" are also Goodw.

8 To clarify, the pleasure one gets from eating chocolate is not about the chocolate in the sense relevant to a recursive account. There is a difference between being pleased that one is 
In other words, Hurka stacks the deck against the conditionality view by allowing basic pleasures to be about pleasures or pains. If we do not count such pleasures as being basic goods, there is no way for Hurka's circularity argument to get off the ground.

A full-fledged alternative recursive account can be given without the troublesome circularity. We can keep Hurka's four recursive principles, (LG), (LE), (HG) and (HE). Logically prior to those, there are four principles for base goods and evils:

(BG1) Arguably, certain types of things that are not pleasures (or pains) are base good. If so, a list must be given.

(BE1) Arguably, certain types of things that are not pains (or pleasures) are base evil. If so, a list must be given.

(BG2) Pleasures that are not about anything, or that are about something that is a) neither a pleasure nor a pain and b) not listed in either (BG1) or (BE1), are good. ${ }^{9}$

(BE2) Pains that are not about anything, or that are about something that is a) neither a pleasure nor a pain and b) not listed in either (BG1) or (BE1), are evil.

None of these base-level principles apply to pleasures or pains that are about other pleasures or pains. This is both elegant and intuitively appropriate - if a pleasure were about a pleasure or a pain, it should be evaluated not by a base-level principle but by a recursive principle. It also avoids the possibility of any circularity in the account. Consider again Hurka's example of an individual $\mathrm{C}$ having sadistic pleasure in B's envious pain in A's pleasure. Either A's pleasure is about a pleasure or pain, or not. If the latter, then A's pleasure is good by (BG), B's pain is evil by (HG) and C's pleasure is evil by (LE) - no circularity there. If A's pleasure is about a pain/pleasure, then its goodness (assuming that it is good) can be determined by the appropriate recursive clause, depending on what its object is. The only way there could be a circularity embedded in the account is if somehow A's pleasure concerned B's pain or C's pleasure - but that is a practical impossibility.

eating chocolate and the gustatory pleasure of eating chocolate. Hurka accepts the category of non-intentional pleasures - he gives an example of "unstructured bodily pleasures" ("How Great a Good Is Virtue?” p. 197). Also see Hurka (2011) The Best Things in Life, New York: Oxford University Press, pp. 17-21 for a catalogue of different orders of pleasures.

${ }^{9}$ In other words, pleasures that are basic goods are those that are either non-intentional or about an object that is neutral. Hurka also accepts this latter category ("How Great a Good Is Virtue?" p. 200); in fact, he argues that the only way for the conditionality view to avoid the circularity argument is to hold that pleasures are not base-level goods, though he claims that that has the counterintuitive implication that pleasures about neutral things are not good. The present recursive view allows for some pleasures to be basic goods simply by excluding the possibility of a base-level pleasure that is about a pleasure or a pain. 
In sum, this recursive account of good and evil, which is more elegant than Hurka's, avoids the circularity problem while demonstrating, in accord with the conditionality view, that pleasures about evils are not good. It is, however, in the same spirit as Hurka's view; Hurka himself writes: "the recursive theory has to start with base-clauses affirming that certain states other than attitudes are intrinsically good and evil." 10 Hurka simply overlooks the fact that base clauses (BG2) and (BE2) can be given instead of (BG) and (BE).

\section{Are There States That Are Both Good and Evil?}

As noted above, a consequence of Hurka's account is that some things are both good and evil. For instance, a sympathetic pain in someone's basic pain is good by $(\mathrm{HE})$ and also evil by $(\mathrm{BE})$. The alternative recursive account stated above avoids this consequence - it seems intuitively odd for a state to be both good and evil, ${ }^{11}$ since good and evil are normally taken to be two ends of a spectrum. However, Hurka gives a nice argument in support of the badness of sympathetic pain. He notes that we have a practice of "sometimes not revealing our hurts to our friends, to spare them the pain of sympathizing with us." 12 If sympathetic pain were a good and not an evil, then we should always go around telling others about pains, at least insofar as we believe that they would feel sympathetic pain.

However, there is a way to modify the above recursive account to avoid that consequence. It is simply to omit (BE1) and have (BE2) change back to:

(BE) [All] Pain is evil.

The two recursive clauses (HG) and (HE) would then simply be omitted. This too avoids any circularity, and it shows, in accord with Hurka's suggestion, that sympathetic pains are evil, without at the same time showing that sympathetic pains are good. There would then be an asymmetry between pains and pleasures, but there is nothing wrong with such an asymmetry.13

Avram Hiller

Portland State University

Department of Philosophy

ahiller@pdx.edu

\footnotetext{
10 “Two Kinds of Organic Unity,” p. 317; also see "How Great a Good Is Virtue?” p. 182.

11 See also Noah Lemos (1998) "Organic Unities," Journal of Ethics 2: 326, n. 14.

12 "How Great a Good Is Virtue?” p. 200.

13 The intuition that sympathetic pains are also good might be explained by the fact that they correlate psychologically with the existence of other states that are good, such as wishing well for someone or helping someone.
} 